\title{
Josimeire de Omena Leite* \\ Cultura crítica e o projeto ético-político do serviço social brasileiro: desafios contemporâneos
}

Critical culture and ethical-political project of the Brazilian social service: contemporary challenges

\begin{abstract}
Resumo: Partindo da premissa de que é no processo de recusa e crítica ao conservadorismo que se encontram as raízes de um novo projeto profissional, este artigo, a partir de revisão bibliográfica, recupera uma importante discussão, presente na atual literatura crítica do Serviço Social brasileiro, acerca dos desafios contemporâneos à profissão. Especificamente aqueles postos ao processo de consolidação de uma cultura crítica no interior do Serviço Social e à efetiva implementação do seu projeto ético-político, num contexto neoliberal. Conclui que apenas mediante uma profunda interlocução da categoria profissional com o marxismo é que se põe concretamente a possibilidade de um olhar crítico sobre o Serviço Social e a apropriação das ferramentas necessárias ao enfrentamento dos novos desafios à consolidação de uma cultura crítica no interior da profissão e ao processo de manutenção da hegemonia do seu projeto ético-político.
\end{abstract}

Palavras-chave: Serviço Social, cultura crítica, projeto ético-político.

Abstract: Assuming that it is in the process of rejection and criticism of conservatism that are the roots of a new professional project, this paper, from bibliographic review recovers an important discussion, present in the current critical literature of the Brazilian social work, about the contemporary challenges of the profession, specifically those positions to the consolidation of a critical culture within the social work and the effective implementation of its ethical-political project, in a neoliberal context. Concludes that only through a profound dialogue in the professional category with Marxism, which is precisely the possibility of a critical view on social work and the appropriation of the necessary tools to face new challenges to the consolidation of a critical culture within the profession and the process of maintaining the hegemony of its ethical-political project.

Keywords: social, cultural criticism, ethical-political project. 
ReVista all paUt:

\} CULTURA CRÍTICA E O PROJETO ÉTICO-POLÍTICO - LEITE, J. O. \}

\section{Introdução}

Tendo como pano de fundo a relação Serviço Social e realidade, as questões aqui apresentadas ressaltam que o Serviço Social vem aprofundando e atualizando a vertente de ruptura com o conservadorismo na profissão e apontam para o fato de que o processo de consolidação de uma cultura crítica no seu interior continua sendo marcado por grandes desafios. Esses se constituem em obstáculos à afirmação da perspectiva crítico-dialética no bojo da profissão e ao processo de manutenção da hegemonia do seu projeto ético-político, na contemporaneidade.

Para dar visibilidade aos atuais desafios à consolidação de uma cultura crítica no interior do Serviço Social, sobretudo num contexto de avanço do pensamento pós-moderno, a reflexão presente neste artigo se delineia a partir das seguintes indagações: quais os desafios que historicamente são postos e repostos à profissão? Quais os desafios que o Serviço Social ainda precisa superar para uma efetiva apropriação de uma racionalidade crítica e o desenvolvimento de uma estratégia de atuação crítica na sua prática cotidiana?

Ao centrar a discussão sobre os principais desafios contemporâneos a uma efetiva implementação do projeto ético-político do Serviço Social brasileiro nos marcos da atual conjuntura, este texto apresentará indicações que irão contribuir para elucidar os seguintes questionamentos: como se delineiam, na cena contemporânea, as ameaças ao aprofundamento do projeto ético-político do Serviço Social e quais as formas de enfrentamento e superação dos limites para a sua implementação na atual conjuntura brasileira?

\section{Serviço Social e realidade: sobre a constituição da vertente crítica do Serviço Social brasileiro}

Em seu livro Ditadura e Serviço Social, José Paulo Netto (1991) remete o seu olhar para o cenário que se delineia no Brasil entre os anos 1960 e 1970. Sua análise chama a atenção do leitor ao indicar que, para uma compreensão da relação entre Serviço Social e a autocracia burguesa, torna-se necessário reportar-se aos novos condicionantes sócio-históricos que, aliados ao significado da autocracia bur-guesa no Brasil, muito influenciaram o fazer e a autorrepresentação profissional. Este autor aprofunda a discussão ao discorrer sobre as "condições novas" (1991, p. 117), apontando para os processos socioeconômicos, que vão desde a reconfiguração do Estado até as transformações societárias, sob a égide do capital na sua fase monopolista, que desencadeou no interior da categoria profissional a chamada modernização conservadora. Esta vem expressar-se, segundo o autor, quando a base que legitima a profissão é redefinida, e isso se dá à medida que são redefinidas as requisições do mercado de trabalho e o quadro da formação do assistente social.

Ainda segundo Netto, é o Estado racionalizado que redimensiona o significado das políticas sociais, criando uma ampla estrutura organizacional para planejá-las e executá-las, visando atender aos interesses da burguesia industrial, que agora requisita um profissional com um perfil "moderno". No entanto, a construção deste novo perfil implicaria igualmente um redimensionamento da formação do assistente social, marcada pelo confessionalismo. Assim, gradativamente são substituídos os 


\section{nevista PII PaUth}

\} CULTURA CRÍTICA E O PROJETO ÉTICO-POLÍTICO - LEITE, J. O. \}

"traços tradicionais" (1991, p. 123) por uma formação norteada pela ótica e racionalidade burguesa sob o influxo das disciplinas vinculadas às ciências sociais, como a sociologia, a antropologia e a psicologia social, para atender aos reclamos do mercado nacional de trabalho.

Neste estudo, o supramencionado autor trata sobre os "vetores de transformação" (1991, p. 136), a culminar na deslegitimação do regime autocrático burguês. Ele denuncia a existência de um paradoxo ao apontar que, à medida que tal regime criava as bases para uma renovação do Serviço Social, gestava, concomitantemente, as circunstâncias favoráveis para uma crítica às bases da autocracia burguesa. Delineia-se, neste cenário, o debate teórico-metodológico, a busca de "legitimação prática e de validação teórica" (1991, p. 131), a crítica aos seus fundamentos, possibilitada pela interlocução com as ciências sociais, e o fato de a ação profissional tornar-se, ela mesma, objeto de investigação. Acresce a isso o delineamento de espaços de reflexão no âmbito universitário, favoráveis ao surgimento de uma massa crítica que se opunha ao conservadorismo na profissão.

Para Netto (1991), a relativa homogeneidade presente na ação profissional, que perdurou até meados dos anos 1960, marcada pela ausência de uma significativa elaboração teórica e participação no cenário político, encontra um terreno infértil no processo de laicização do Serviço Social, que ganha expressão no contexto do desenvolvimento das relações capitalistas, no trâmite da chamada "modernização conservadora". A análise salienta o fato de que a renovação do Serviço Social irá trazer ao novo cenário os elementos mais marcantes que são a introdução de um pluralismo teórico, ideológico e político no bojo da profissão - revelando a não homogeneidade de concepções e de práticas do Serviço Social. Contribuem para esse processo a interlocução com disciplinas das ciências sociais, intentando romper com a "subalternidade intelectual" e a formação de uma vanguarda dedicada à pesquisa e culmina com o gradativo reconhecimento do Serviço Social como área de investigação e produção de conhecimento.

Em Netto (1991), ganhando profundidade nos estudos de Ammann (1991), constata-se a heterogeneidade das correntes teórico-ideológicas, que coexistiam e se confrontavam (no âmbito teórico), materializada nas três vertentes do desenvolvimento de comunidade. A primeira, que reitera os procedimentos "tradicionais" embasada numa visão acrítica e a-histórica da realidade brasileira, reduzida aos limites da pequena localidade, estimula uma "participação" que manipula as classes subalternas. A segunda concebe a participação numa perspectiva macrossocietária que anseia provocar as mudanças estruturais, úteis à expansão capitalista no Brasil, não criando um vínculo orgânico com a classe subalterna; e, finalmente, a terceira vertente, que entende as comunidades não como um "todo único e harmônico", mas sim como uma realidade onde estão presentes forças antagônicas regidas por relações sociais de dominação. Para esta, a participação adquire um novo significado: a luta pela hegemonia das classes subalternas.

Vê-se que, nos marcos da reconceituação, a interlocução de segmentos da profissão com o marxismo, apesar das fragilidades iniciais, possibilita um olhar crítico sobre a profissão e sobre a conjuntura sócio-histórica brasileira e de outros países da América Latina - já que a renovação se delineia como um fenômeno latino-

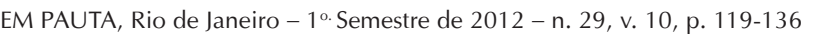




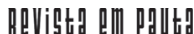

\} CULTURA CRÍTICA E O PROJETO ÉTICO-POLÍTICO - LEITE, J. O. \}

americano. É essa interlocução, segundo o autor (1991), que permite a visibilidade dos embates no interior da categoria profissional, fazendo-se a distinção entre os segmentos profissionais "modernizantes" e aqueles que requisitavam uma ruptura com o Serviço Social tradicional.

Como conclui Netto, é na tensão de vetores de transformação e permanência que se vislumbra o novo:

A dialética entre o Serviço Social no país antes e durante/depois do ciclo autocrático não é nem a ruptura íntegra nem a mesmice pleonástica: é um processo muito complexo em que rompimentos se entrecruzam e se superpõem a continuidades e reiterações; é uma tensão de vetores de transformação e permanência - e todos comparecem, em medida desigual e metamorfoseadas, na resultante em que, indubitavelmente, predomina o novo. (1991, p. 136).

Noutras palavras, a estratégia da autocracia burguesa para a intervenção profissional atender aos reclamos do mercado nacional de trabalho, neste momento histórico, criou as bases que precipitaram a ruptura com o Serviço Social "tradicional". Para Netto (1991), este fenômeno deve ser analisado no contexto de lutas contra o imperialismo, libertação nacional e tentativa de superação da ordem capitalista.

A partir de meados dos anos 1970, num contexto de crise do regime militar, a heterogeneidade no interior da categoria profissional está posta pela presença de segmentos profissionais cuja intervenção se funda na perspectiva modernizadora e por aqueles segmentos que buscam reatualizar a sua herança conservadora, embasando suas ações na vertente fenomenológica, numa postura acrítica e a-histórica.

A heterogeneidade no interior da categoria profissional explicita-se também com a aproximação da profissão ao marxismo, possibilitada pela influência do Movimento de Reconceituação do Serviço Social Latino-Americano em meados dos anos de 1960, numa crítica aos pressupostos teórico-metodológicos positivistas que resultava na desmistificação da suposta neutralidade do profissional, denunciava uma sociedade dividida em classes antagônicas e apontava para a possibilidade do compromisso profissional com o projeto societário de uma das classes sociais: da classe dominante ou da classe subalterna. Vale ressaltar que num contexto em que a profissão começa a questionar, seja seus métodos tradicionais, seja sua eficácia numa realidade marcada pelo desenvolvimentismo e, posteriormente, pelo questionamento da sua vinculação histórica com os interesses da classe dominante, é que se delineiam, segundo Netto (1991), as seguintes matrizes para o Serviço Social: matriz tradicional e conservadora, modernização conservadora e a chamada ruptura com o conservadorismo. As duas últimas, sob forte influência do Movimento de Reconceituação do Serviço Social na América Latina a partir dos anos 1960.

Tal movimento, aliado a uma conjuntura sócio-histórica marcada pela crise da ditadura militar e pela redemocratização da sociedade civil, criou as bases para o processo de renovação crítica no interior do Serviço Social brasileiro que, na 


\section{neVistg PII PaUth}

\} CULTURA CRÍTICA E O PROJETO ÉTICO-POLÍTICO - LEITE, J. O. \}

década de 1980, viabiliza o delineamento de uma cultura crítica fundada, segundo Netto (1999), numa vertente crítica inspirada na tradição marxista. Esse processo irá impulsionar uma ruptura profissional com o conservadorismo e o delineamento de um novo projeto ético-político do Serviço Social, agora comprometido com o projeto societário da classe trabalhadora. ${ }^{1}$

O III Congresso Brasileiro de Assistentes Sociais, ocorrido no ano de 1979, em São Paulo, conhecido como o "Congresso da Virada", legitimou uma nova direção teórico-prática e ético-política para a profissão. Segundo Netto (1999), esse projeto ganhou hegemonia no interior da categoria profissional na década de 1990, com sua efetiva participação em fóruns e eventos profissionais. Estavam postas, assim, as condições objetivas para o entendimento da existência de uma diferenciação, no interior da categoria profissional, no que se refere às posições teleológicas, posturas ético-políticas e habilidades técnico-instrumentais que refletem diferentes concepções teóricas e ideopolíticas sobre a profissão e sobre a sociedade, tão bem explicitadas por Trindade (1999).

Netto (2005), ao ressaltar a importância do Movimento de Reconceituação, no contexto da América Latina, para a constituição da vertente crítica do Serviço Social, faz referência ao Serviço Social crítico que, no Brasil, deu origem ao projeto ético-político. Em seus estudos, o autor chama a atenção para o fato de que "[...] é neste processo de recusa e crítica do conservadorismo que se encontram as raízes de um projeto profissional novo" (2009, p. 1); no entanto, percebe-se que o delineamento de uma cultura crítica no interior do Serviço Social foi marcado por grandes desafios que, efetivamente, criaram obstáculos à afirmação da perspectiva críticodialética no interior da profissão. Desafios estes que se atualizam e rebatem no processo de materialização de alguns princípios e valores que fundam o Projeto ÉticoPolítico do Serviço Social, na contemporaneidade.

\section{Desafios à consolidação de uma cultura crítica no interior do Serviço Social no Brasil}

Alguns autores, dentre eles Guerra (2000), convergem ao apontar para a importância de o Serviço Social, como profissão interventiva, apropriar-se de uma racionalidade crítica, investindo numa instrumentalidade inspirada pela razão dialética que permita o conhecimento que ultrapasse a aparência imediata dos processos sociais, bem como o desenvolvimento de uma intervenção crítica, não restrita às ações meramente instrumentais, buscando construir alternativas que sejam instrumentais à superação da ordem burguesa. Mas quais os desafios que historicamente são postos e repostos à profissão? Quais os desafios que o Serviço Social ainda precisa superar para uma efetiva apropriação desta racionalidade e para o desenvolvimento de uma estratégia de atuação crítica na sua prática cotidiana?

Os estudos de Maranhão (2006) são muito elucidativos e nos remetem, respaldados em Netto, para um complexo de determinações que obstaculizaram a afirma-

\footnotetext{
${ }^{1}$ Segundo lamamoto (2009), o Serviço Social construiu um projeto profissional crítico e inovador, que se materializa no Código de Ética, na Lei que regulamenta a profissão, ambos de 1993, e nas Diretrizes Curriculares (1996), que norteiam a formação acadêmica.
}

EM PAUTA, Rio de Janeiro - 10. Semestre de 2012 - n. 29, v. 10, p. 119-136

Revista da Faculdade de Serviço Social da Universidade do Estado do Rio de Janeiro 


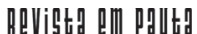

\} CULTURA CRÍTICA E O PROJETO ÉTICO-POLíTICO - LEITE, J. O. \}

ção da perspectiva crítico-dialética no interior da profissão no Brasil até o final dos anos 1970; para a aproximação incipiente e "enviesada" do Serviço Social, até meados dos anos 1980, com o arcabouço teórico-cultural da tradição marxista, que culminou na frágil apreensão dos pressupostos teórico-metodológicos da teoria social de Marx; bem como para o espraiamento, a partir dos anos 1990, de um pensamento neoconservador, pós-moderno, que valoriza o pragmatismo e o subjetivismo que levam à "reposição intelectual do sincretismo profissional" (MARANHÃO, 2006, p. 30).

Maranhão (2006) chama a atenção para o fato de que "[...] as determinações que dificultam a fluidez das análises críticas no interior da profissão deitam raízes [...] na própria constituição do ser socioprofissional do Serviço Social" (p. 6). O autor, ao aprofundar-se na análise de tais determinações, traz à luz enormes desafios que marcaram o Serviço Social no contexto da chamada "modernização conservadora", bem como o Serviço Social crítico.

A nosso ver, são desafios que extrapolam a simples vontade dos sujeitos sociais, de reafirmar os fundamentos históricos ontológicos da profissão. Tal assertiva encontra respaldo em Netto quando afirma que são obstáculos histórico-sociais que passam pela questão da natureza socioprofissional. Esta, permeada pela estrutura sincrética que balizou a afirmação e o desenvolvimento do Serviço Social como profissão e pela tentativa de rompimento da absorção da teoria marxista, que se deu de forma vulgarizada e reduzida a um "epistemologismo de raiz estruturalista", impossibilitando o desvendar das mediações próprias a cada espaço interventivo. Tais obstáculos são agravados pelo recrudescimento das características manipulatórias do capitalismo maduro, que entravam a elaboração de um conhecimento em busca da totalidade social (apud MARANHÃO, 2006, p. 22).

Ao debruçar-se sobre tais desafios, o referido autor chama a atenção para o fato de que o Serviço Social possui um estatuto: sua intervenção e desenvolvimento atrelam-se à demanda histórica de manutenção da ordem capitalista. Tal assertiva encontra respaldo em Netto quando este explicita que a profissão surge vocacionada "para subsidiar a administração da questão social" nos marcos da sociedade burguesa e esta se dá com trânsito na gestão e manipulação de variáveis empíricas e que, para a tradição marxista, a superação da questão social requer a superação da sociedade capitalista (IDEM, p. 14).

Assim, pois, ao lidar com as refrações da questão social, os profissionais são compelidos a intervir parcialmente, recorrendo aos procedimentos burocrático-administrativos para, num mais puro pragmatismo, dar respostas imediatas às demandas que se apresentam no cotidiano institucional, tendo a sua intervenção um fim em si mesma. Como observa Maranhão (2006), ao se manipular as variáveis empíricas, nos moldes das análises lógico-formal-abstratas, exalta-se a razão instrumental como a forma legítima de se conhecer o real.

Indubitavelmente, a ação profissional pautada numa racionalidade instrumental cria as condições para uma lacuna entre o projeto ético-político da profissão e a prática cotidiana do assistente social, pois favorece uma subalternidade desse profissional às demandas institucionais e aos interesses imediatos dos empregadores, impedindo uma plena adesão aos princípios e valores contidos no referido projeto. 


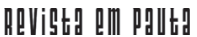

\} CULTURA CRÍTICA E O PROJETO ÉTICO-POLÍTICO - LEITE, J. O. \}

Entre eles, a saber: o reconhecimento da liberdade como valor ético central; o posicionamento em favor da cidadania, da democracia, equidade e justiça social; o compromisso com a emancipação e com a plena expansão dos indivíduos sociais; a socialização da participação política e da riqueza produzida socialmente; o compromisso com a qualidade dos serviços prestados à população; a publicização dos recursos institucionais; a gestão democrática, entre outros (CFESS, 1993). Vale acrescentar que o projeto ético-político do Serviço Social vincula-se explicitamente a um projeto societário cuja proposta é a construção de uma nova ordem societária, sendo demandada à profissão uma veemente oposição a toda e qualquer forma de exploração e/ou dominação, seja de classe, de gênero ou de etnia.

Vale ressaltar, no entanto, que nos marcos da sociedade burguesa, existe a possibilidade de que sejam estruturadas estratégias de atuação crítica "comprometidas com o desvelamento das reais condições históricas de existências de práticas institucionais burguesas e com a defesa do avanço dos direitos conquistados pelos trabalhadores" (MARANHÃO, 2006, p. 24). Porém, para este desvelar, o Serviço Social ainda enfrenta outro desafio, que é, no campo investigativo, desvendar as tendências ideopolíticas e culturais do pensamento pós-moderno que afrontam o pensamento fundado na ontologia, desprezam a "dimensão ontológica do real, da história como substância", proclamam "o fim da história e das grandes narrativas" (MARANHÃO, 2006, p. 29) e defendem o debruçar-se sobre os fatos empíricos do cotidiano e as ações profissionais restritas ao caráter técnico-funcional. Vale ressaltar que tais ações reordenam condutas no interior da instituição e manipulam variáveis, tendo como horizonte a eficiência e a eficácia dos resultados.

Ainda segundo o autor, entra em cena o desafio contemporâneo que se coloca no centro do debate epistemológico ou ontológico: o avanço do pensamento pósmoderno, que encontra raízes nas determinações histórico-sociais marcadas por um racionalismo burguês que se delineia num contexto de crise estrutural do capital. Para o mesmo, é o espraiar-se da cultura irracionalista do imediato, um modo de pensar que coloca no mesmo plano a essência e a aparência, revelando-se incapaz de acessar as determinações e a essencialidade do fenômeno social e de criar estratégias de intervenção crítica, numa mera reposição do sincretismo profissional (MARANHÃO, 2006).

Concorda-se com Maranhão quando enfatiza que só com a apreensão do método dialético é que haverá uma real aproximação do assistente social com a totalidade dos processos sociais e a criação de "uma ferramenta, um instrumental de acesso às múltiplas determinações que compõem a realidade social através da reprodução mental de processos reais" (2006, p. 31). E, dessa forma, possibilitando o desenvolvimento de estratégias de atuação que superem toda e qualquer forma de atuação acrítica e apolítica.

O referido autor ainda observa que uma atuação crítica comporta outras mediações, como as correlações de forças políticas no interior do espaço de atuação profissional. Acrescenta-se a essa constatação aquelas mediações que não se restringem ao espaço institucional, mas que, num amplo processo de correlação de forças, perpassam o conjunto da categoria profissional em sua intervenção nos mais diversos campos de atuação, sem perder de vista o fato de que o desenvolvimento 
ReVista all paUtid

\} CULTURA CRÍTICA E O PROJETO ÉTICO-POLíTICO - LEITE, J. O. \}

de novas estratégias de intervenção, teórico-metodológicas e ideopolíticas - numa perspectiva crítica que permita ir além das "reposições intelectuais do sincretismo" - depende de "uma densa retomada do procedimento de ir aos fundamentos ontológicos, de recuperar a essência das coisas" (2006, p. 30), num contexto sócio-histórico marcado pela exaltação do virtual, do efêmero, do simulacro e do simbólico, como fatores explicativos e estruturantes da realidade social.

\section{Desafios contemporâneos ao projeto ético-político do Serviço Social: uma aproximação ao debate}

O ciclo fordista de acumulação capitalista entra em declínio na década de 70 do século XX, após um período de altas taxas de acumulação de capital pós-Segunda Guerra Mundial. A queda da taxa média de lucros dos países, os claros sinais de esgotamento dos mercados, o recrudescimento do desemprego e a elevação das taxas inflacionárias demandaram as chamadas políticas de austeridade monetária e fiscal, bem como uma acirrada busca de reformas de ordem geral, impulsionando um novo estágio de desenvolvimento do capitalismo, a nível mundial. Delineia-se, nesse cenário, um conjunto de medidas propostas pelos organismos multilaterais, tendo por fundamento uma reforma orientada pelo mercado.

É a partir dos anos 1990, num contexto marcado pela crise e reestruturação produtiva do capital, que se vislumbram profundas mudanças no mundo do trabalho e a efetivação de medidas governamentais, de cunho neoliberal, a provocar grandes transformações na sociedade brasileira e um alto custo social. Tais transformações vêm impondo novos desafios ao Serviço Social, que se delineiam nesse contexto de crise. Vale ressaltar que a crise estrutural do capital "[...] não se confunde com qualquer versão catastrófica sobre o fim do capitalismo" (MOTA, 2010, p. 14) e que as respostas para o seu enfrentamento resultaram em profundas mudanças no Brasil, nas dimensões econômica, política, social e cultural, com evidentes reflexos no Estado e nas políticas sociais.

É a partir da análise desse novo contexto sócio-histórico que a literatura contemporânea do Serviço Social, fundada na teoria social de Marx, aponta para o fato de que a cultura neoliberal constitui-se, por um lado, numa ameaça ao aprofundamento do projeto ético-político da profissão. Mas, por outro, o alto custo social dela decorrente vem fortalecer a tese de que os valores contidos no novo projeto profissional, concatenados ao projeto societário da classe trabalhadora, são atuais e relevantes para o combate ao ideário neoliberal.

A partir desse entendimento, cabe por ora a seguinte indagação: como se delineiam, na cena contemporânea, as ameaças ao aprofundamento do projeto ético-político do Serviço Social e quais as formas de enfrentamento e superação dos limites para a sua implementação na atual conjuntura brasileira?

Os estudos de Netto (2009), lamamoto (2004; 2009), Mota (2010), Mota e Amaral (2009), Silva e Silva (2009) e Teixeira e Braz (2009) são muito elucidativos, pois trazem à luz uma pertinente discussão sobre os principais desafios contemporâneos ao projeto ético-político do Serviço Social brasileiro nos marcos da atual conjuntura. 


\section{neVista PII PaUth}

\} CULTURA CRÍTICA E O PROJETO ÉTICO-POLÍTICO - LEITE, J. O. \}

Numa primeira aproximação a esta discussão, identifica-se nos estudos de Netto que, enquanto o movimento democrático e popular brasileiro alçava voos e, em sintonia, o Serviço Social construía o seu projeto ético-político, uma crise social mundial irrompia na passagem dos anos 1980 aos 1990, e que a partir de meados dos anos 90 do século XX,

[...] as práticas político-econômicas inspiradas no neoliberalismo e a sua cultura viram-se amplamente disseminadas no conjunto da sociedade [...] a grande burguesia brasileira reciclou rapidamente seu projeto societário, tornando-se defensora do neoliberalismo [...] uma ameaça real à implementação do projeto profissional do Serviço Social (2009, p. 21-22).

Silva e Silva (2009) também faz um interessante resgate dos desafios contemporâneos à implementação do projeto ético-político que passam pelas metamorfoses do capital, pelas recentes mudanças no mundo do trabalho e pelo ideário neoliberal, que se tornou hegemônico no Brasil a partir dos anos 1990 do século XX, numa explícita defesa de um Estado que protege os interesses da classe dominante. Este que vem, segundo Mota, exercitando-se como classe dirigente, "[...] implementando seu projeto classista através de uma direção restauradora, criando (reinventando) iniciativas conservadoras sob o influxo de ideias liberais" (2010, p. 16).

Os recentes estudos sobre o Serviço Social brasileiro e o projeto ético-político profissional revelam que o Estado brasileiro, neste novo contexto sócio-histórico, vem se tornando mínimo no que tange à garantia dos interesses da classe trabalhadora, e máximo na defesa dos interesses do capital financeiro, dos grupos industriais transnacionais e dos grandes investidores. Este novo cenário se apresenta como um terreno fértil para "[...] o descompasso do projeto profissional, constituindose num desafio para uma minoria que dá a direção estratégica para a profissão" (SILVA E SILVA, 2009, p. 30).

Mota (2010) contribui significativamente para um melhor entendimento desta questão, quando faz uma análise da conjuntura brasileira que se delineia a partir das últimas décadas do século XX. A autora discorre sobre a crise estrutural do capital e o caráter mundial desta crise, demonstra como o capital procura enfrentar as suas contradições a partir dos anos 1980, e como o Estado brasileiro passa, a partir de meados dos anos 1990, a desempenhar um protagonismo ao desencadear um processo de contrarreforma cujo fim é a garantia dos lucros exorbitantes das oligarquias financeiras e econômicas que controlam os rumos da produção capitalista.

Em sua investigação, a supracitada autora destaca "[...] o papel das classes dominantes no seu ímpeto restaurador", apontando para o "novo movimento constitutivo da hegemonia das classes dominantes, desenvolvido com as armas da despolitização em prol da conservação dos interesses daquela classe", no qual a "pequena política" ganha força e expressão. Nas palavras de Mota (2010, p. 17; 21):

O que ora presenciamos é outra pedagogia de socialização da sociedade brasileira em que as demandas dos 'de baixo' são

EM PAUTA, Rio de Janeiro - 10. Semestre de 2012 - n. 29, v. 10, p. 119-136 


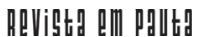

\} CULTURA CRÍTICA E O PROJETO ÉTICO-POLÍTICO - LEITE, J. O. \}

atendidas no âmbito da 'pequena política' (Coutinho, 2010, p.

29) como meio de sitiar a 'grande política' (Coutinho, 2010, p.

41). Este movimento comporta a convivência com os novos movimentos sociais e com algumas das reivindicações de necessidades sociais, como o acesso à renda e ao consumo (MOTA, 2010, 22).

No âmbito desta discussão, Mota ainda chama a atenção para o fato de que o governo Lula, ao buscar responder à luta histórica contra a desigualdade social, com estratégias que escamoteiam o antagonismo de classe - na tentativa de obter o consentimento de uma considerável parte dos trabalhadores -, desistoriciza a pobreza. Isto porque adotou como estratégias para o seu enfrentamento as políticas de cunho compensatório, sem deixar de atender às exigências da classe dominante e sem colocar em xeque a exploração capitalista:

A contrarreforma do período Lula, ao mesmo tempo que é restauração das bases de acumulação sob a égide do bom capitalismo, também é 'reforma-social e moral' porque, desta feita, algumas das necessidades da pobreza são atendidas sem que isso signifique romper com a desigualdade e colocar em questão a exploração capitalista (2010, p. 24).

Esclarecedor é o estudo de Mauriel (2010, p. 174), quando anota que "a reestruturação da noção de política social em direção aos mais pobres, cada vez mais distante da concepção de seguridade, aconteceu vinculada a outros aspectos fundamentais: a mudança do estatuto teórico da questão social, que passa a ser cada vez mais reduzida à pobreza". Nesta direção, a crítica desenvolvida por Behring sobre o Estado no neoliberalismo também é bastante elucidativa, ressaltando a

emersão de uma espécie de clientelismo (pós) moderno ou de neocorporativismo, onde a sociedade civil é domesticada [...] por meio da distribuição e disputa dos parcos recursos públicos para ações focalizadas ou da seleção de projetos sociais pelas agências multilaterais (2008, p. 65).

Enfim, há uma rica produção teórica do Serviço Social que faz uma crítica efetiva às diretrizes de cunho neoliberal que propiciaram o ajuste estrutural no Brasil. Em especial, elas se dirigem: ao gradativo processo de retração do Estado na provisão das políticas sociais; ao processo de responsabilização da sociedade civil na provisão das necessidades sociais e à remercantilização dos direitos e das políticas sociais, em que o mercado sai fortalecido pelo favorecimento do setor privado, com a criação de verdadeiros nichos para a venda dos serviços sociais em decorrência da degradação dos serviços públicos.

lamamoto assevera que um grande desafio para a efetivação do projeto éticopolítico profissional neste atual cenário "é torná-lo um guia efetivo para o exercício 


\section{neVista PII PaUth}

\} CULTURA CRÍTICA E O PROJETO ÉTICO-POLÍTICO - LEITE, J. O.\}

profissional [...] o que exige um radical esforço de integrar o dever ser com sua implementação prática, sob o risco de se deslizar para uma proposta ideal, abstraída da realidade histórica". (2004, p. 26). Para tanto, a autora menciona a necessária articulação das dimensões organizativas, acadêmicas e legais que dão sustentabilidade a esse projeto com a realidade do trabalho cotidiano do profissional, principalmente numa conjuntura adversa ao desenvolvimento deste.

Isso significa que os (as) assistentes sociais devem intervir nas expressões da questão social com um posicionamento ético-político e técnico orientado pelos princípios e valores propugnados pelo projeto ético-político da profissão, buscando favorecer os interesses da classe trabalhadora, seja no contato cotidiano com os usuários, seja nos processos de participação e controle social, seja nas ações de assessoria, planejamento ou gestão. Para fazer frente ao novo projeto de restauração da ordem do capital, a atuação profissional deve pautar-se, também, pela busca do fortalecimento da prática político-organizativa da categoria e pela luta visando à manutenção da autonomia de suas organizações.

A adesão dos últimos governos ao projeto neoliberal, a partir dos anos 1990 do século XX, favoreceu o delineamento de um contexto marcado pelo recuo do movimento democrático e popular brasileiro, pela degradação das condições de trabalho e dos serviços públicos, e pelo desmonte dos direitos. Constituía-se, assim, como observam Silva e Silva, um verdadeiro entrave e "uma ameaça real à implementação do projeto profissional do Serviço Social [...] para o exercício profissional qualificado e orientado por fundamentos éticos consagrados no projeto". (2009, p. 29).

A partir do exposto, chama a atenção o fato de que a articulação das dimensões organizativas, acadêmicas e legais que sustentam o projeto ético-político com a realidade do trabalho cotidiano do assistente social, põe e repõe novos desafios. $\mathrm{E}$, isto, principalmente quando

[...] a profissão tem um ideário que se revela no projeto éticopolítico-profissional, responsável pela direção social que desejamos e lutamos para imprimir à nossa ação, mas sua operatividade depende das condições objetivas, nem sempre favoráveis (MOTA; AMARAL, 2009, p. 53).

Os estudos de lamamoto conferem profundidade a esta discussão quando apontam para a existência de uma tensão entre projeto profissional e trabalho assalariado, ressaltando que

embora o assistente social disponha de uma relativa autonomia na [...] condução de seu trabalho - o que lhe permite atribuir uma direção social ao exercício profissional -, os organismos empregadores também interferem no estabelecimento de metas a atingir (2004, p. 22).

Isto porque as exigências advindas dos mais diversos empregadores, no âmbito da organização social e técnica do trabalho, condicionam o trabalho realizado 


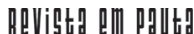

\} CULTURA CRítICA E O PROJeTO ÉTICO-POLÍTICO - LEITE, J. O. \}

pelo assistente social e conferem li-mites e possibilidades à realização dos objetivos profissionais. A nosso ver, tal constatação parte do entendimento da existência de uma determinante central que é o ingresso do trabalho profissional na divisão sociotécnica do trabalho capitalista.

Recuperando esta discussão, Mota (2010) destaca a inexistência de uma identidade imediata entre a intencionalidade do projeto ético-político profissional e os resultados decorrentes de sua efetivação. Chama a atenção para a questão dos limites da autonomia profissional em face da sua condição de trabalhador assalariado, cujo processo de mercantilização da força de trabalho impõe limites à autonomia do assistente social no desenvolvimento do seu trabalho e à implementação integral do projeto profissional. Nas palavras de lamamoto:

Verifica-se uma tensão entre 'projeto profissional' que afirma o assistente social como um ser prático-social dotado de liberdade e teleologia, capaz de realizar projeções e buscar implementá-las na vida social; e a condição de trabalhador assalariado, cujas ações são submetidas ao poder dos empregadores e determinadas por condições externas aos indivíduos singulares, às quais são socialmente forjados a subordinar-se, ainda que coletivamente possam rebelar-se (apud MOTA, 2010, p. 30).

Tal constatação remete à questão da dimensão política da profissão, que implica a autonomia do projeto profissional - esta, por sua vez, não pode ser reduzida à "pequena política" dos governos neoliberais ou à "[...] 'contrapolítica' dos técnicos, que se pretende asséptica e neutra, mas afirma o instituído" (NOGUEIRA apud IAMAMOTO, 2009, p. 36) -, e que,

[...] também implica a decisão de ultrapassar a 'pequena política do dia-a-dia', tal como se expressa na competência permitida e autorizada pelas organizações, restrita à prática manipulatória imediata e à recepção passiva das informações. Esta se traduz no empirismo, nas rotinas, no burocratismo que reiteradamente se repõem no trabalho profissional (IAMAMOTO, 2009, p. 37).

É inconteste a contribuição das recentes produções teóricas do Serviço Social no âmbito do marco teórico, já mencionado, quando estas indicam os desafios que a profissão precisa superar para o desenvolvimento de uma estratégia de atuação crítica na prática cotidiana na instituição. Guerra (2000) e Maranhão (2006) insistem que a profissão Serviço Social deve investir, em condições adversas, numa instrumentalidade inspirada pela razão crítico-dialética que comporte a contradição, a totalidade e as mediações, buscando desenvolver estratégias teórico-metodológicas e ideopolíticas para a superação do sincretismo e atentando para as determinações histórico-sociais, econômicas, políticas e ideológicas presentes em sua atuação profissional. Mota também ressalta que, 


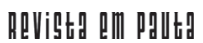

\} CULTURA CRÍTICA E O PROJETO ÉTICO-POLÍTICO - LEITE, J. O. \}

[...] os limites da autonomia técnico-profissional não se confundem com as possibilidades de construção de uma consciência crítica das relações que marcam a inserção dos assistentes sociais no mundo do trabalho profissional [...] o sujeito profissional pode enriquecer suas objetivações e, como qualquer trabalhador assalariado, acionar práticas político-organizativas de resistência e luta que tenham incidência na mudança dos processos reais onde se localiza o cotidiano profissional. (2010, p. 31).

Já lamamoto destaca que o esforço de integrar o "dever ser" com a objetivação do projeto profissional - que contém em si uma direção social de caráter éticopolítico e é indissociável dos projetos societários - supõe "impregnar o exercício profissional da 'grande política'." (2009, p. 36).

Indubitavelmente, os desafios postos pela atual conjuntura à efetivação do projeto ético-político profissional expressam um conjunto de determinações que, para serem enfrentadas, prescindem de sua compreensão. Afinal, os históricos desafios colocados ao Serviço Social originam-se na "contraditória determinação social da profissão" (MOTA, 2010, p. 25), e que são, segundo a autora, complexos e de ordem teórica, ético-política e prático-operativa.

É nesta direção que todos os autores aqui mencionados, ao desvelarem os atuais desafios postos ao processo de aprofundamento e consolidação de uma cultura crítica no interior do Serviço Social, bem como à implementação do seu projeto ético-político, dão uma efetiva contribuição, apontando os caminhos para o enfrentamento e a superação de tais desafios.

Autores que, por um lado, reconhecem ser a realidade atual desfavorável e que, nesta conjuntura adversa, "o projeto ético-político encontra-se num momento crucial de sua trajetória [...] porque remete à manutenção ou não das bases teóricas, organizativas e ético-políticas do projeto coletivo da profissão" (TEIXEIRA; BRAZ, 2009, p. 197); mas, por outro lado, contrapõem-se veementemente àqueles profissionais que acreditam na "crise" ou na "inviabilidade" do projeto ético-político, sob o argumento de que este "[...] apresenta princípios que não podem ser efetivados concretamente e que o fazer profissional não permite que sejam contemplados" (IDEM, p. 194).

Vale destacar o trabalho de Mota e Amaral, pois nesse, as autoras oferecem uma valiosa contribuição ao debate quando explicitam que o projeto ético-político do Serviço Social não está em crise, mas se encontra "[...] tensionado e determinado pela crise orgânica mundial do capital" (2010, p. 54) e pela ofensividade dos mecanismos capitalistas de restauração desta crise. Teixeira também contribui significativamente quando assevera que é possível a consolidação do projeto éticopolítico do serviço social, que tem capacidade de balizar a formação e o exercício profissional em defesa da democracia, dos direitos sociais e do combate à desigualdade social, vinculado "a um projeto civilizatório superior" (2009, p. 18), numa perspectiva de construção de uma nova sociabilidade.

Ao entendê-lo como um desafio, mas não uma impossibilidade (IAMAMOTO, 2004), os estudos que se ancoram na tradição marxista anunciam que o projeto éti-

EM PAUTA, Rio de Janeiro - 10. Semestre de 2012 - n. 29, v. 10, p. 119-136 
ReVista all paUtid

\} CULTURA CRítICA E O PROJETO ÉTICO-POLÍTICO - LEITE, J. O. \}

co-político do Serviço Social tem futuro, em sua perspectiva teórica, histórica, ética e ideopolítica,

[...] porque aponta precisamente para o combate (ético, teórico, ideológico, político e prático-social) ao neoliberalismo, de modo a preservar e atualizar os valores que [...] o informam e o tornam solidário ao projeto de sociedade que interessa à massa da população. (NETTO, 2009, p. 22).

Com um olhar atento sobre a atual conjuntura brasileira, a literatura crítica do Serviço Social, ao debruçar-se sobre os desafios contemporâneos à implementação do projeto ético-político profissional e ao afirmar que a questão de fundo é a autonomia (IAMAMOTO, 2009; SILVA E SILVA, 2009; MOTA, 2010; NETTO, 2004), conclama os assistentes sociais a fortalecerem a sua prática político-organizativa, chamando a atenção para a luta necessária à manutenção da autonomia de suas organizações - fruto de conquista teórica e ideopolítica da categoria nas últimas décadas -, que deve ser travada nesta conjuntura adversa, preservando-a "contra ventos e marés [...] para conduzir e aprofundar as exigências do projeto éticopolítico [...]." (NETTO, 2004, p. 24).

Trata-se, como vimos, de uma conjuntura marcada pela crise do capital financeiro internacional cuja profundidade e as respostas para o seu enfrentamento põem na ordem do dia a exigência da implementação de "[...] um novo projeto de restauração da ordem do capital" (MOTA, 2010, p. 19), que vem provocando intensas mudanças no cenário mundial, tanto na dimensão econômica como nas dimensões política, social e cultural.

Diante do exposto, destaca-se que os autores supramencionados concordam entre si com o fato de que o projeto ético-político é um processo em construção. Netto, ao tratar sobre a estrutura básica do novo projeto profissional, enfatiza que este não tem exclusividade no interior da categoria profissional e não está "consumado", pois ainda "[...] não se desenvolveram suficientemente as suas possibilidades" (1999, p. 106). Nesta mesma direção, Teixeira (2009, p. 19) destaca que este "não está dado", sendo, portanto, colocada, para os (as) assistentes sociais, a exigência de um permanente esforço de aperfeiçoamento intelectual, estratégico e táticooperativo.

Por fim, percebe-se que a profissão Serviço Social é determinada por relações sociais e que os limites e as possibilidades presentes no cotidiano da prática profissional são determinadas pelas condições estruturais da sociedade capitalista. Assim, pois, para se entender a dinâmica desta sociedade e construir estratégias de intervenção teórico-metodológicas e ideopolíticas à luz dos princípios e valores contidos no projeto ético-político da profissão - como resistência à barbarização da vida social -, faz-se necessário pensar esta realidade numa perspectiva de totalidade. E, nesta, as estratégias devem ser fruto da elaboração de um pensamento crítico, da capacidade dos assistentes sociais de decifrar as contradições presentes na atual sociedade capitalista, e que devem estar articuladas às lutas imediatas e históricas da classe trabalhadora. 


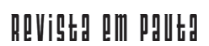

\} CULTURA CRÍTICA E O PROJETO ÉTICO-POLÍTICO - LEITE, J. O. \}

\section{Considerações finais}

A revisão bibliográfica apresentada neste artigo vem contribuir para o debate existente sobre o projeto ético-político do Serviço Social, na medida em que dá visibilidade aos grandes desafios colocados à afirmação da perspectiva crítico-dialética no bojo da profissão. Demonstra, também, que tais desafios se atualizam e incidem no processo de materialização de alguns princípios e valores que fundam o projeto ético-político do Serviço Social na contemporaneidade.

As produções teóricas aqui analisadas conferem aos assistentes sociais a compreensão de que o enfrentamento daqueles desafios postos ao processo de consolidação de uma cultura crítica no interior do Serviço Social e a efetiva implementação do seu projeto ético-político só será possível se remetido ao entendimento da crise estrutural do capital e das respostas a ela das pelas classes dominantes. Isso implica um debruçar-se sobre a crise e a reestruturação produtiva do capital que leve em conta as recentes mudanças no mundo do trabalho e o espraiar-se do ideário neoliberal, que impulsionaram, nos países periféricos, as chamadas reformas institucionais.

Os estudos apresentados são elucidativos por chamarem a atenção dos profissionais para o perigo da disseminação, no conjunto da sociedade, das práticas inspiradas no neoliberalismo e de sua cultura, bem como por advertirem quanto ao avanço do pensamento pós-moderno, que indubitavelmente afronta o pensamento fundado na ontologia, despreza a dimensão ontológica do real e defende a ação profissional pautada numa racionalidade instrumental. Também possibilitam aos profissionais a compreensão de que o projeto ético-político do Serviço Social não está em crise, como alguns afirmam, mas se encontra tensionado e determinado pela crise estrutural do capital e pela ofensiva dos mecanismos capitalistas de restauração dessa crise mundial. Demonstram ainda que um grande desafio para a efetivação do projeto ético-político profissional no atual contexto é torná-lo um guia efetivo para o exercício profissional, o que requer um grande esforço para integrar o dever-ser com sua efetivação, para que aquele não incorra numa proposta ideal.

A revisão da literatura, aqui apresentada, contribui significativamente para o tema tratado, na medida em que demonstra que os autores estudados não se limitam a apresentar as ameaças ao aprofundamento do projeto ético-político da profissão, mas, numa perspectiva de totalidade social, indicam caminhos para o enfrentamento e a superação dos atuais desafios, a fim de que o debate da categoria não resvale para um otimismo descabido ou para um fatalismo que leva à inércia. Assim, este estudo reafirma que, apenas mediante uma profunda interlocução da categoria profissional com o marxismo, munindo-se dos seus pressupostos teórico-metodológicos, é que se põe concretamente a possibilidade de um olhar atento e crítico acerca da profissão. Este olhar deve considerar as atuais condições em que se efetivam a formação e o exercício profissional, bem como a apropriação das ferramentas necessárias para o enfrentamento das questões postas à consolidação de uma cultura crítica no interior do Serviço Social e à efetiva implementação do seu projeto éticopolítico.

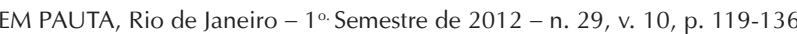




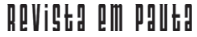

\} CULTURA CRÍTICA E O PROJETO ÉTICO-POLÍTICO - LEITE, J. O. \}

A nosso ver, o debate não está esgotado, pois diante da ofensiva do capital, no seu ímpeto restaurador, os desafios à consolidação de uma cultura crítica no interior da profissão são postos e repostos. Isso coloca na ordem do dia a veemente necessidade de novos estudos para desencadear um contínuo processo de discussão e compreensão dos atuais limites e possibilidades para a efetivação dos princípios e valores contidos no projeto ético-político do Serviço Social na cena contemporânea. As principais mediações para isso já estão postas. 


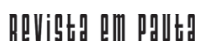

\} CULTURA CRÍTICA E O PROJETO ÉTICO-POLÍTICO - LEITE, J. O.

\section{Referências}

AMMANN, S. B. Ideologia e desenvolvimento de comunidade no Brasil. São Paulo: Cortez, 1991.

BEHRING, E. R Brasil em contra-reforma: desestruturação do Estado e perda de direitos. 2a. ed. São Paulo: Cortez, 2008.

CFESS. Código de ética profissional do assistente social. Brasília: CFESS, 1993.

GUERRA, Y. Instrumentalidade no trabalho do assistente social. In: CFESS/ABEPSS. Capacitação em serviço social e política social. Módulo 4: O trabalho do assistente social e as políticas sociais. [Curso de especialização à distância em políticas sociais]. Brasília. UnB, ABEPSS/CFESS/CEAD/NED/UnB, 2000.

IAMAMOTO, M. V. As dimensões ético-políticas e teórico-metodológicas no Serviço Social contemporâneo. [Texto base da conferência magistral]. XVIII Seminário Latinoamericano de escuelas de trabajo social. San José, Costa Rica, 12 jul. 2004. Disponível em: <http://www.fnepas.org.br/pdf/servico_social_saude/texto2-2.pdf>. Acesso em: 23 ago. 2011.

. O Serviço Social na cena contemporânea. In: CFESS/ABEPSS. Serviço Social: direitos sociais e competências profissionais. Curso de Capacitação à distância. Brasília: CFESS/ABEPSS/UnB-CEAD, 2009.

MARANHÃO, C. H. M. C. Sincretismo, tradição marxista e estratégias de atuação profissional: ensaio sobre a importância histórico-ontológica dos fundamentos para a ruptura com o conservadorismo no Serviço Social. Recife, 2006, mimeo.

MAURIEL, A. P. Pobreza, seguridade e assistência social: desafios da política social brasileira. Revista Katálysis. v. 13, n. 2, p. 173-180, jul/dez. 2010.

MOTA, A. E. Redução da pobreza e aumento da desigualdade: um desafio teóricopolítico ao Serviço Social brasileiro. In: MOTA, A. E. (Org.). As ideologias da contrarreforma e o Serviço Social. Recife: Ed.Universitária da UFPE, 2010.

; AMARAL, Â. Profissão: projeto profissional e projeto societário. In: Revista Inscrita. CFESS, Brasília, 2009.

NETTO, J. P. Ditadura e Serviço Social: uma análise do Serviço Social no Brasil pós64. São Paulo: Cortez, 1991.

A conjuntura brasileira: o Serviço Social posto à prova. In: Serviço Social \& Sociedade. São Paulo: Cortez. Especial, n. 79, p. 61-74, 2004.

. O movimento de reconceituação: 40 anos depois. In: Serviço Social \& Sociedade. São Paulo: Cortez, n. 84, 2005.

. A construção do projeto ético-político profissional. In: CFESS/ABEPSS; $\overline{\mathrm{CEAD} / U n \mathrm{n}}$ (Org.). Crise contemporânea, questão social e serviço social. Capacitação em Serviço Social e política social: Módulo1. Brasília: CEAD/UnB, 1999.

EM PAUTA, Rio de Janeiro - ${ }^{\text {o. }}$ Semestre de 2012 - n. 29, v. 10, p. 119-136 


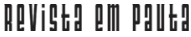

\} CULTURA CRÍTICA E O PROJETO ÉTICO-POLÍTICO - LEITE, J. O. \}

SILVA E SILVA, M. O. Trinta anos da revista Serviço Social e Sociedade: contribuições para o desenvolvimento do Serviço Social no Brasil. Serviço Social e Sociedade 100. São Paulo: Cortez, 2009.

TEIXEIRA, J.B. Da barbárie ao paraíso. In: Revista Inscrita. CFESS, Brasília, 2009. ; BRAZ, M. O projeto ético-político do Serviço Social. In: CFESS/ABEPSS.

Serviço Social: direitos sociais e competências profissionais. Curso de Capacitação à distância. Brasília: CFESS/ABEPSS; UnB/CEAD, 2009.

TRINDADE, R. L. P. Desvendando o significado do instrumental técnico-operativo na prática profissional do Serviço Social. [Tese de Doutorado].Rio de Janeiro, UFRJ/ ESS, 1999.

Recebido em 24 de maio de 2012.

Aceito para publicação em 21 de agosto de 2012. 